University of Nebraska - Lincoln

DigitalCommons@University of Nebraska - Lincoln

USDA National Wildlife Research Center - Staff Publications
U.S. Department of Agriculture: Animal and Plant Health Inspection Service

2012

\title{
Carrion cycling in food webs: comparisons among terrestrial and marine ecosystems
}

James C. Beasley

Purdue University, beasley@srel.uga.edu

Z. H. Olson

Purdue University

T. L. DeVault

USDA/APHIS/WS National Wildlife Research Center, Travis.L.DeVault@aphis.usda.gov

Follow this and additional works at: https://digitalcommons.unl.edu/icwdm_usdanwrc

Part of the Life Sciences Commons

Beasley, James C.; Olson, Z. H.; and DeVault, T. L., "Carrion cycling in food webs: comparisons among terrestrial and marine ecosystems" (2012). USDA National Wildlife Research Center - Staff Publications. 1078.

https://digitalcommons.unl.edu/icwdm_usdanwrc/1078

This Article is brought to you for free and open access by the U.S. Department of Agriculture: Animal and Plant Health Inspection Service at DigitalCommons@University of Nebraska - Lincoln. It has been accepted for inclusion in USDA National Wildlife Research Center - Staff Publications by an authorized administrator of DigitalCommons@University of Nebraska - Lincoln. 
Oikos 121: 1021-1026, 2012

doi: $10.1111 / j .1600-0706.2012 .20353 . x$

No claim to original US government works. Oikos (C) 2012 Nordic Society Oikos

Subject Editor: James D. Roth. Accepted 3 February 2012

This article is a U.S. government work, and is not subject to copyright in the United States.

\title{
Carrion cycling in food webs: comparisons among terrestrial and marine ecosystems
}

\author{
James C. Beasley, Z. H. Olson and T. L. DeVault \\ J. C. Beasley (beasley@purdue.edu) and Z. H. Olson, Dept of Forestry and Natural Resources, 195 Marstellar Street, Purdue Univ., \\ West Lafayette, IN 47907, USA. - T. L. DeVault, US Dept of Agriculture, Animal and Plant Health Inspection Service, Wildlife Services, \\ National Wildlife Research Center, Ohio Field Station, 6100 Columbus Avenue, Sandusky, OH 44870, USA.
}

\begin{abstract}
In light of current global changes to ecosystem function (e.g. climate change, trophic downgrading, and invasive species), there has been a recent surge of interest in exploring differences in nutrient cycling among ecosystem types. In particular, a growing awareness has emerged concerning the importance of scavenging in food web dynamics, although no studies have focused specifically on exploring differences in carrion consumption between aquatic and terrestrial ecosystems. In this forum we synthesize the scavenging literature to elucidate differences in scavenging dynamics between terrestrial and marine ecosystems, and identify areas where future research is needed to more clearly understand the role of carrion consumption in maintaining ecosystem function within each of these environments. Although scavenging plays a similar functional role in terrestrial and aquatic food webs, here we suggest that several fundamental differences exist in scavenging dynamics among these ecosystem types due to the unique selection pressures imposed by the physical properties of water and air. In particular, the movement of carcasses in marine ecosystems (e.g. wave action, upwelling, and sinking) diffuses biological activity associated with scavenging and decomposition across large, three-dimensional spatial scales, creating a unique spatial disconnect between the processes of production, scavenging, and decomposition, which in contrast are tightly linked in terrestrial ecosystems. Moreover, the limited role of bacteria and temporal stability of environmental conditions on the sea floor appears to have facilitated the evolution of a much more diverse community of macrofauna that relies on carrion for a higher portion of its nutrient consumption than is present in terrestrial ecosystems. Our observations are further discussed as they pertain to the potential impacts of climate change and trophic downgrading (i.e. removal of apex consumers from ecosystems) on scavenging dynamics within marine and terrestrial ecosystems.
\end{abstract}

In recent years a growing body of literature has emerged underscoring the importance of scavenging in food web dynamics, calling for a paradigm shift in how ecologists delineate nutrient cycling among trophic levels within and across ecosystems (DeVault et al. 2003, Selva and Fortuna 2007, Wilson and Wolkovich 2011). In particular, the use of carrion by vertebrates through facultative scavenging is much more widespread than implied by conventional theory, resulting in the underestimation of scavenging by as much as 16-fold in food-web research (Wilson and Wolkovich 2011). Such underestimation of scavengingderived links in food webs is not a trivial omission, because scavengers serve an important function as stabilizing forces in food webs (DeVault et al. 2003) and play critical roles in the redistribution of nutrients among ecosystems (Payne and Moore 2006). Moreover, scavenged carrion resources can create hotspots of biological diversity that last for years, increasing landscape heterogeneity and the spatial complexity of ecosystems (Towne 2000, Smith and Baco 2003, Carter et al. 2007, Bump et al. 2009).
In light of current global changes to ecosystem function (e.g. climate change, trophic downgrading, and invasive species) there has been a surge of interest in understanding differences (and commonalities) in the cycling of nutrients among ecosystem types (Chase 2000, Shurin et al. 2006, Nowlin et al. 2008, Van der Wal and Hessen 2009). In particular, much focus has been devoted to contrasting food-web dynamics between terrestrial and aquatic ecosystems; however, no studies have focused specifically on carrion consumption. Although there are similarities in scavenging activities between terrestrial and aquatic ecosystems, fundamental differences exist in the way animal carcasses are cycled in each of these food webs. Here we synthesize the major differences in scavenging between terrestrial and aquatic ecosystems to highlight the importance of carrion consumption as a factor affecting nutrient cycling within each of these ecosystem types. We also discuss the potential effects of climate change and trophic downgrading (i.e. removal of apex consumers from ecosystems - Estes et al. 2011) on scavenging dynamics and 
identify areas where future research is needed. Compared to information available from marine ecosystems (reviewed by Britton and Morton 1994), there are few data concerning the fate of carrion in freshwater habitats (Minshall et al. 1991). Thus, in this paper we concentrate on marine systems, particularly abyssal ecosystems which comprise $>50 \%$ of the earth's surface (Smith et al. 2008); although many of the general patterns associated with marine scavenging undoubtedly apply to fresh-water lakes and rivers as well.

\section{Spatial dynamics of carrion resources}

The primary differences in the cycling of carrion resources between terrestrial and aquatic ecosystems are directly attributable to emergent properties of water and air. The higher relative density of water and the three-dimensional nature of aquatic ecosystems allows for the movement of carrion, either by wave action, upwelling, or most notably, sinking (Britton and Morton 1994), whereas carrion produced on land remains relatively unmoved throughout the processes of scavenging and decomposition. This basic truism has many consequences for the way ecosystems in water and on land operate, including the mechanisms influencing the evolution of scavenging behavior in both ecosystem types.

Movement of carcasses in marine ecosystems diffuses the biological activity associated with scavenging and decomposition across larger, three-dimensional spatial scales than occurs on land (Allison et al. 1991, Rowe and Staresinic 1979, Carter et al. 2007). First, the mechanical action of waves and currents in shallow marine environments diffuses the concentration of nutrients and particulates that result from scavenging and decomposition, limiting the intensity of any localized response in primary production to the occurrence of a carcass (Burkepile et al. 2006). Second, carcasses in pelagic environments may sink fairly rapidly through the zone of primary production to depths inaccessible to most pelagic scavengers, enforcing a time-limit on the recruitment (i.e. a functional response) of scavengers to a carcass that otherwise would represent a considerable resource (DeVault et al. 2003). Thus, in these ecosystems the dilute and ephemeral flush of nutrients associated with a carcass can be contrasted with what is a spatially constrained and relatively intense biological signal associated with carcasses in terrestrial ecosystems (Janzen 1977, Carter et al. 2007, Melis et al. 2007).

The added vertical dimension in marine environments deserves special consideration as a unique scenario in scavenging ecology. This fundamental physical difference between terrestrial and marine scavenging maintains a limit on the amount of time a carcass is available for scavenging by the pelagic community (where most carrion resources are generated), but has facilitated the evolution of a diverse assemblage of scavengers associated with the benthic environment in the deep-sea. For example, nearly 200 species of macrofauna have colonized a single whale carcass at densities of up to 45000 individuals per square meter (Smith and Baco 2003), whereas macrofaunal species assemblages capable of colonizing or scavenging terrestrial carcasses appear to approach only half that richness (Tabor et al. 2005, Selva et al. 2005). The presence and persistence of these deep-sea scavengers is inextricably linked to the availability of nekton, or raining organic matter, from the surface (Gooday et al. 1990, Britton and Morton 1994, Smith et al. 2008). This vertical separation of the deep-sea benthic scavenger community from its source of nutrient production in the photic zone above represents an interesting spatial disconnect between the processes of production, scavenging, and decomposition, which in contrast are tightly linked in terrestrial ecosystems (Wardle et al. 2004). For example, in terrestrial environments the nutrients associated with scavenging and decomposition are rapidly recycled by primary producers at or near the carcass location (Towne 2000, Payne and Moore 2006, Bump et al. 2009), while interactions between abyssal depths and zones of primary productivity can be measured on evolutionary time-scales (Smith et al. 2008).

\section{Competition for carrion}

Vertebrates, invertebrates, and bacteria all compete for carrion resources, although the competitive hierarchy among these diverse assemblages of organisms differs between terrestrial and marine ecosystems. Terrestrial environments undergo dramatic temporal changes in weather (both daily and seasonally), influencing the ability of each of these groups of organisms to compete for carrion, and resulting in temporal shifts in scavenger community composition. For example, during periods of warm weather the activity of smaller ectothermic organisms such as insects and bacteria is maximized, significantly reducing scavenging rates by terrestrial vertebrates (DeVault et al. 2004, Selva et al. 2005, Parmenter and MacMahon 2009). However, bacteria monopolization of carrion in terrestrial ecosystems also may be influenced by the composition and abundance of invertebrate species, which can produce inhibitory secretions that attenuate microorganism growth on carrion (Hall et al. 2011). Conversely, temperature fluctuations in marine (particularly abyssal) ecosystems are minimized by the large heat capacity of water (Steele 1985). Thus, relative efficiencies in carrion consumption by various taxa in marine ecosystems are not regulated by climate shifts to the degree that they are on land. As a result, evolutionary pressures, namely competition between vertebrate, invertebrate, and bacterial scavengers, undoubtedly differ between terrestrial and marine environments.

Bacteria are able to effectively compete with scavengers by producing toxic and objectionable chemicals that can render carcasses unpalatable to animals in as little as 24 h (Janzen 1977, DeVault et al. 2004, Burkepile et al. 2006). However, bacterial growth is strongly limited by temperature and pressure (Jannasch 1978), thus microbes do not appear as capable of monopolizing carrion resources in marine ecosystems as effectively as on land (Gooday et al. 1990, Allison et al. 1991; but see Burkepile et al. 2006). For example, due to low temperatures and increased pressure at abyssal ocean depths, a single cetacean carcass can provide food for several years to hundreds of thousands of scavengers comprising nearly 200 species (Smith and Baco 2003), whereas a carcass of similar size on land can be rendered useless to vertebrates within days by insects and microbes (Coe 1978, Carter et al. 2007). This persistence of carrion on the sea bed through reduced microbial 
activity appears to be a vital component to the evolution and maintenance of high levels of biodiversity in abyssal ecosystems.

Despite the prolific and diverse community of scavengers supported within deep-sea ecosystems, researchers have speculated that marine ecosystems should not support the evolution of obligate scavengers owing to the spatial and temporal unpredictability of carrion on the sea floor (Britton and Morton 1994). However, contrary to such theory, recent research demonstrates that many deep-sea species have evolved physiological and behavioral traits conducive to a scavenging lifestyle, suggesting that some deep-sea animals may in fact be obligate scavengers (i.e. they rely on carrion for survival) and many likely rely on necrophagy for a large portion of their diet (Kaiser and Moore 1999, Tamburri and Barry 1999, Smith and Baco 2003). For example, mobile scavengers (e.g. the hagfishes) have evolved highly sensitive chemoreceptive abilities which allow them to detect distant carrion resources and have the ability to survive a year or more between meals (Smith 1985, Tamburri and Barry 1999). Despite these recent discoveries, the dietary habits of most abyssal scavengers remain poorly understood due to the difficulties of monitoring free-ranging individuals in benthic ecosystems, and thus scavenging ecology in the deep-sea remains an area of much needed research. Similarly, vertebrate scavenging likely plays an important role in nutrient cycling in other marine environments, yet little is known regarding scavenging behavior in these ecosystems. For example, although carrion often is not commonly available in coral reef ecosystems, Rassweiler and Rassweiler (2011) recently demonstrated that the absence of carrion in these ecosystems is due to rapid (within $24 \mathrm{~h}$ ) consumption by fish, rather than a lack of carrion inputs.

Although competition between vertebrates and microbes for carrion resources is more pronounced in terrestrial ecosystems, the ability of bacteria to monopolize carrion on land varies spatially with both altitude and latitude as a function of ambient air temperature. As a result, the role of carrion consumption in maintaining facultative scavenger populations on land likely differs among ecosystems (DeVault et al. 2011), although little is known about the importance of scavenging in many terrestrial ecosystems. Spatial variability in microbial activity also may exist in oceans between abyssal and surface or tropical and arctic ecosystems, although even in tropical marine ecosystems microbial monopolization of carcasses likely is limited due to the rapid attenuation of carrion by vertebrates (Smith 1985, Jones et al. 1998).

In addition to the ephemeral nature of carrion resources on land, most terrestrial scavengers have increased energetic costs associated with locating carrion relative to scavengers in aquatic environments. As a result of these additional constraints, most terrestrial vertebrates appear to utilize carrion opportunistically (DeVault et al. 2003); only large, soaring birds (i.e. vultures) have evolved as obligate carrion consumers (Ruxton and Houston 2004; see also Shivik 2006). Nonetheless, necrophagy is pervasive among terrestrial organisms and energy derived through scavenging may play a central role in the survival and distribution of many species (Houston 1978, Wilmers et al. 2003a, b). In particular, carrion consumption by vertebrates in temperate climates is greatest during winter, owing to the reduced activity of microbes (DeVault et al. 2004, Selva et al. 2005), and thus nutrients obtained through scavenging may play a critical role in the overwinter survival and development of offspring (Gese et al. 1996a, b, Wilmers et al. 2003b); although empirical research is needed to test this intriguing hypothesis.

\section{Broader ecological impacts}

Given the important role carrion consumption plays in numerous ecological processes such as mitigating disease spread (Pain et al. 2003, Jennelle et al. 2009) and maintaining food-web stability (DeVault et al. 2003, Wilson and Wolkovich 2011), there is an emerging need to elucidate how anthropogenic perturbations to ecosystems (e.g. trophic downgrading, climate change, pollution, invasive species) influence the efficiency and resiliency of scavenging communities. In a striking example that demonstrates the importance of scavenging communities, accidental poisoning of vultures at carcasses has disrupted scavenging communities in Africa (Virani et al. 2011) and India (Green et al. 2004), resulting in cascading effects on ecosystem services and human health (Markandya et al. 2008).

Climate change in particular represents an acute threat to the stability of scavenging communities worldwide (Smith et al. 2008, Wilson and Wolkovich 2011), although the impacts of climate change on scavenger community composition likely will vary among ecosystems. Given that decomposition rates for carrion double for roughly every $10^{\circ} \mathrm{C}$ increase in temperature (Vass et al. 1992, Parmenter and MacMahon 2009), the availability of carrion to terrestrial macrofauna could decline by $20-40 \%$ over the next century based on current projections from climate change models due to increased microbial activity. Thus, increasing temperatures on land likely will disproportionately favor microbes, potentially reducing terrestrial biodiversity by limiting species dependent on carrion for critical food (Houston 1978, Wilmers et al. 2003a, b, Ruxton and Houston 2004) and breeding (Rozen et al. 2008) resources. Although reduced carrion availability likely will have widespread implications among terrestrial ecosystems, the impacts could be particularly acute in polar ecosystems due to the critical role that carrion plays in overwinter survival and breeding success of some species (Fuglei et al. 2003).

Although increased temperatures are likely to alter scavenging community dynamics on land, effects of climate change presumably also will be widespread and detrimental to organisms in deep-sea ecosystems due to their inextricable link to surface productivity. For example, in marine ecosystems projected climate change models indicate that surface production of organic material could decline by more than $50 \%$, drastically reducing the availability of resources to food-limited abyssal ecosystems (Smith et al. 2008). Such a dramatic decrease in food availability undoubtedly would constrain populations of benthic scavengers, potentially reducing biodiversity on the sea floor. 
Indeed, macrofaunal assemblages already have declined in response to a decrease in food resources exported to benthic ecosystems and concurrent increases in bottom-water temperatures due to increasing global temperatures in recent years (Bergmann et al. 2011).

The prevalence and distribution of infectious disease also is expected to increase in both terrestrial and aquatic ecosystems with rising global temperatures (Patz et al. 1996, Harvell et al. 2002), decreasing the relative temporal stability of carrion by producing pulses of animal death. Such increases in the presence of uneaten carcasses could pose a direct threat to human, livestock, and wildlife health by increasing the prevalence of infectious disease (Pain et al. 2003, Markandya et al. 2008). Although there are excellent examples of population responses driven by resource pulses in terrestrial environments (Ostfeld and Keesing 2000, Schmidt and Ostfeld 2008), it is generally expected that aquatic communities will be better adapted than terrestrial communities to respond numerically to pulses of high-quality resources such as carcass falls (Hill and Wassenberg 2000, Ramsey et al. 1997, Nowlin et al. 2008, Weston et al. 2008). Thus, the consequences of altered temporal stability of carrion likely will be most severe in terrestrial ecosystems, where many scavenger communities are naive to pulses of carrion (although see Reimchen 2000 for a discussion of salmon-bear interactions in North America) and some species may be averse to consuming non predator-killed carcasses (Selva et al. 2005, but see Houston 1979, DeVault et al. 2003), which may alter the efficiency of terrestrial food webs and further facilitate the spread of disease (Pain et al. 2003, Markandya et al. 2008, Jennelle et al. 2009).

The ability of terrestrial communities to compensate for such pulses in carrion availability may be strongly linked to the level of disturbance within the predator community (Olson et al. 2011) as apex predators serve important ecosystem services through minimizing disease outbreaks (Jackson et al. 2001, Estes et al. 2011) and maintaining populations of facultative scavengers by providing access to essential food resources (Houston 1978, Wilmers et al. 2003a, b). Thus, the effects of climate change on terrestrial ecosystems may be minimized in ecosystems with intact predator communities through the stabilization of carrion availability (Wilmers and Post 2006, Terborgh et al. 2001). Indeed, recent empirical studies in terrestrial ecosystems have demonstrated that scavenging efficiency is highly sensitive to perturbations in scavenging community composition (Wilmers and Post 2006, Olson et al. 2011).

Similarly, continued anthropogenic assaults to the mean trophic level of marine ecosystems (i.e. fishing down the food web; Pauly et al. 1998) undoubtedly will alter scavenging dynamics in these ecosystems as well. Particular to abyssal systems, research has previously linked large shifts in scavenger species diversity and abundance to changes to the composition of the plankton community in the photic zone above (Bett et al. 2001, Billett et al. 2001, Wigham et al. 2003). Thus, the estimated and projected impacts of ongoing trophic downgrading in oceans (Estes et al. 2011) likely will continue to cascade though deeper waters to reach scavenging communities in abyssal ecosystems.
Experimental research quantifying the impacts of trophic downgrading on scavenging dynamics should be a focus of future foodweb research in both terrestrial and marine ecosystems.

\section{Conclusions}

Although carrion consumption plays a similar functional role in terrestrial and aquatic food webs, several fundamental differences exist in scavenging dynamics among these ecosystem types due to the unique selection pressures imposed by the physical properties of water and air. In particular, the limited role of bacteria and temporal stability of environmental conditions on the sea floor appears to have facilitated the evolution of a much more diverse community of macrofauna that relies on carrion for a higher portion of its nutrient consumption than is present in terrestrial ecosystems. Nonetheless, despite the additional constraints of scavenging on land, carrion consumption is pervasive among macrofauna in terrestrial ecosystems (DeVault et al. 2003, Selva and Fortuna 2007), suggesting that scavenging is a vital means of acquiring nutrients for many species regardless of their functional role in food webs.

There is no doubt that both terrestrial and aquatic organisms across the globe face immense challenges in the face of widespread human perturbations to ecosystems (Terborgh et al. 2001, Estes et al. 2011). Although recent research has greatly improved our understanding of the role of carrion consumption in the structuring and stability of both terrestrial and aquatic food webs, there is a need to elucidate the role of scavenging in broader ecosystem processes. In particular, understanding the mechanisms governing differences in carrion cycling among ecosystems will be essential to developing strategies to mitigate the effects of human activities on global ecosystem function (Wenny et al. 2011). Although the impact of altered carrion availability is obvious for species that are obligate (or primarily) carrion consumers or breeders, the majority of species utilize carrion opportunistically. Thus, a clear understanding of the impact of carrion availability on the ecology, distribution, and persistence of facultative scavengers will be essential to the future management and conservation of numerous taxa.

Acknowledgements - We thank Olin E. Rhodes, Jr. and Bradley F. Blackwell for critically reviewing previous drafts of this manuscript. Financial support was provided by the Purdue University Department of Forestry and Natural Resources, USDA-APHIS-WS National Wildlife Research Center, and by the U.S. Department of Energy through contract number DE-FC09-96SR18546 with the University of Georgia's Savannah River Ecology Laboratory.

\section{References}

Allison, P. A. et al. 1991. Deep-water taphonomy of vertebrate carcasses: a whale skeleton in the bathyal Santa Catalina basin. - Paleobiology 17: 78-89.

Bergmann, M. et al. 2011. The interannual variability of megafaunal assemblages in the Arctic deep sea: preliminary results from the HAUSGARTEN observatory $\left(79^{\circ} \mathrm{N}\right)$. - Deep-Sea Res. I 58: 711-723. 
Bett, B. J. et al. 2001. Temporal variability in phytodetritus and megabenthic activity at the seabed in the deep Northeast Atlantic. - Prog. Oceanogr. 50: 349-368.

Billett, D. S. M. et al. 2001. Long-term change in the megabenthos of the Porcupine Abyssal Plain (NE Atlantic). - Prog. Oceanogr. 50: 325-348.

Britton, J. C. and Morton, B. 1994. Marine carrion and scavengers. - Oceanogr. Mar. Biol. Annu. Rev. 32: 369-434.

Bump, J. K. et al. 2009. Wolves modulate soil nutrient heterogeneity and foliar nitrogen by configuring the distribution of ungulate carcasses. - Ecology 90: 3159-3167.

Burkepile, D. E. et al. 2006. Chemically mediated competition between microbes and animals: microbes as consumers in food webs. - Ecology 87: 2821-2831.

Carter, D. O. et al. 2007. Cadaver decomposition in terrestrial ecosystems. - Naturwissenschaften 94: 12-24.

Chase, J. M. 2000. Are there real differences among aquatic and terrestrial food webs? - Trends Ecol. Evol. 15: 408-412.

Coe, M. 1978. The decomposition of elephant carcases in the Tsavo (East) National Park, Kenya. - J. Arid Environ. 1: 71-86.

DeVault, T. L. et al. 2003. Scavenging by vertebrates: behavioral, ecological, and evolutionary perspectives on an important energy transfer pathway in terrestrial ecosystems. - Oikos 102: 225-234.

DeVault, T. L. et al. 2004. Factors influencing the acquisition of rodent carrion by vertebrate scavengers and decomposers. - Can. J. Zool. 82: 502-509.

DeVault, T. L. et al. 2011. Mesopredators dominate competition for carrion in an agricultural landscape. - Basic Appl. Ecol. 12: $268-274$.

Estes, J. A. et al. 2011. Trophic downgrading of planet earth. - Science 333: 301-306.

Fuglei, E. et al. 2003. Local variation in arctic fox abundance on Svalbard, Norway. - Polar Biol. 26: 93-98.

Gese, E. M. et al. 1996a. Social and nutritional factors influencing the dispersal of resident coyotes. - Anim. Behav. 52: $1025-1043$.

Gese, E. M. et al. 1996b. Foraging ecology of coyotes (Canis latrans): the influence of extrinsic factors and a dominance hierarchy. - Can. J. Zool. 74: 769-783.

Gooday, A. J. et al. 1990. Responses by benthic organisms to inputs of organic material to the ocean floor: a review. - Phil. Trans. R. Soc. A 331: 119-138.

Green, R. E. et al. 2004. Diclofenac poisoning as a cause of vulture population declines across the Indian subcontinent. - J. Appl. Ecol. 41: 793-800.

Hall, C. L. et al. 2011. Inhibition of microorganisms on a carrion breeding resource: the antimicrobial peptide activity of burying beetle (Coleoptera: Silphidae) oral and anal secretions. - Environ. Entomol. 40: 669-678.

Harvell, C. D. et al. 2002. Climate warming and disease risks for terrestrial and marine biota. - Science 296: 2458-2162.

Hill, B. J. and Wassenberg, T. J. 2000. The probable fate of prawn discards from trawlers fishing near coral reefs - a study in the northern Great Barrier Reef, Australia. - Fish. Res. 48: $277-286$.

Houston, D. B. 1978. Elk as winter-spring food for carnivores in northern Yellowstone National Park. - J. Appl. Ecol. 15: 653-661.

Houston, D. C. 1979. The adaptations of scavengers. - In: Sinclair, A. R. E. and Griffiths, M. N. (eds), Serengeti, dynamics of an ecosystem. Univ. of Chicago Press, pp. 263-286.

Jackson, J. B. C. et al. 2001. Historical overfishing and the recent collapse of coastal ecosystems. - Science 293: 629-638.

Jannasch, H. W. 1978. Experiments in deep-sea microbiology. - Oceanus 21: 50-57.

Janzen, D. H. 1977. Why fruits rot, seeds mold, and meat spoils. - Am. Nat. 111: 691-713.
Jennelle, C. et al. 2009. Deer carcass decomposition and potential scavenger exposure to chronic wasting disease. - J. Wildlife Manage. 73: 655-662.

Jones, E. G. et al. 1998. The fate of cetacean carcasses in the deep sea: observations on consumption rates and success of scavenging species in the abyssal northeast Atlantic Ocean. - Proc. R. Soc. B 265: 1119-1127.

Kaiser, M. J. and Moore, P. G. 1999. Obligate marine scavengers: do they exist? - J. Nat. Hist. 33: 475-481.

Markandya, A. et al. 2008. Counting the cost of vulture decline an appraisal of the human health and other benefits of vultures in India. - Ecol. Econ. 67: 194-204.

Melis, C. et al. 2007. Soil and vegetation nutrient response to bison carcasses in Bialowieza Primeval Forest, Poland. - Ecol. Res. 22: 807-813.

Minshall, G. W. et al. 1991. Decomposition of rainbow trout (Oncorhynchus mykiss) carcasses in a forest stream ecosystem inhabited only by nonanadromous fish populations. - Can. J. Fish. Aquat. Sci. 48: 191-195.

Nowlin, W. H. et al. 2008. Comparing resource pulses in aquatic and terrestrial ecosystems. - Ecology 89: 647-659.

Olson, Z. H. et al. 2011. Scavenger community response to the removal of a dominant scavenger. - Oikos 121: 77-84.

Ostfeld, R. S. and Keesing, F. 2000. Pulsed resources and community dynamics of consumers in terrestrial ecosystems. - Trends Ecol. Evol. 15: 232-237.

Pain, D. J. et al. 2003. Causes and effects of temporospatial declines of Gyps vultures in Asia. - Conserv. Biol. 17: 661-671.

Parmenter, R. R. and MacMahon, J. A. 2009. Carrion decomposition and nutrient cycling in a semiarid shrub-steppe ecosystem. - Ecol. Monogr. 79: 637-661.

Patz, J. A. et al. 1996. Global climate change and emerging infectious diseases. - J. Am. Med. Ass. 275: 217-223.

Pauly, D. et al. 1998. Fishing down marine food webs. - Science 279: 860-863.

Payne, L. X. and Moore, J. W. 2006. Mobile scavengers create hotspots of freshwater productivity. - Oikos 115: 69-80.

Ramsey, K. et al. 1997. Consumption of fisheries discards by benthic scavengers: utilization of energy subsidies in different marine habitats. - J. Anim. Ecol. 66: 884-896.

Rassweiler, A. and Rassweiler, T. 2011. Does rapid scavenging hide non-predation mortality in coral-reef communities? - Mar. Freshwater Res. 62: 510-515.

Reimchen, T. E. 2000. Some ecological and evolutionary aspects of bear-salmon interactions in coastal British Columbia. - Can. J. Zool. 78: 448-457.

Rowe, G. T. and Staresinic, N. 1979. Sources of organic matter to the deep-sea benthos. - Ambio Spec. Rep. 6: 19-23.

Rozen, D. E. et al. 2008. Antimicrobial strategies in burying beetles breeding on carrion. - Proc. Natl Acad. Sci. USA 105: $17890-17895$.

Ruxton, G. D. and Houston, D. C. 2004. Obligate vertebrate scavengers must be large soaring fliers. - J. Theor. Biol. 228: 431-436.

Schmidt, K. A. and Ostfeld, R. S. 2008. Numerical and behavioral effects within a pulse-driven system: consequences for shared prey. - Ecology 89: 635-646.

Selva, N. and Fortuna, M. A. 2007. The nested structure of a scavenger community. - Proc. R. Soc. B 274: 1101-1108.

Selva, N. et al. 2005. Factors affecting carcass use by a guild of scavengers in European temperate woodland. - Can. J. Zool. 83: $1590-1601$

Shivik, J. A. 2006. Are vultures birds, and do snakes have venom, because of macro- and microscavenger conflict? - Bioscience 56: 819-823.

Shurin, J. B. et al. 2006. All wet or dried up? Real differences between aquatic and terrestrial food webs. - Proc. R. Soc. B 273: 1-9. 
Smith, C. R. 1985. Food for the deep sea: utilization, dispersal, and flux of nekton falls at the Santa Catalina Basin floor. - Deep-Sea Res. I 32: 417-442.

Smith, C. R. and Baco, A. R. 2003. Ecology of whale falls at the deep-sea floor. - Oceanogr. Mar. Biol. Annu. Rev. 41: 311-354.

Smith, C. R. et al. 2008. Abyssal food limitation, ecosystem structure and climate change. - Trends Ecol. Evol. 23: 518-528.

Steele, J. H. 1985. A comparison of terrestrial and marine ecological systems. - Nature 313: 355-358.

Tabor, K. L. et al. 2005. Insect fauna visiting carrion in southwest Virginia. - Forensic Sci. Int. 150: 73-80.

Tamburri, M. N. and Barry, J. P. 1999. Adaptations for scavenging by three diverse bathyla species, Eptatretus stouti, Neptunea amianta and Orchomene obtusus. - Deep-Sea Res. I 46: 2079-2093.

Terborgh, J. et al. 2001. Ecological meltdown in predator-free forest fragments. - Science 294: 1923-1926.

Towne, E. G. 2000. Prairie vegetation and soil nutrient responses to ungulate carcasses. - Oecologia 122: 232-239.

Van der Wal, R. and Hessen, D. O. 2009. Analogous aquatic and terrestrial food webs in the high Arctic: the structuring force of a harsh climate. - Perspect. Plant Ecol. 11: 231-240.

Vass, A. A. et al. 1992. Time since death determinations of human cadavers using soil solution. - J. Forensic Sci. 37: 1236-1253.
Virani, M. Z. et al. 2011. Major declines in the abundance of vultures and other scavenging raptors in and around the Masai Mara ecosystem, Kenya. - Biol. Conserv. 144: 746-752.

Wardle, D. A. et al. 2004. Ecological linkages between aboveground and belowground biota. - Science 304: 1629-1633.

Wenny, D. G. et al. 2011. The need to quantify ecosystem services provided by birds. - Auk 128: 1-14.

Weston, N. H. et al. 2008. Comparing resource pulses in aquatic and terrestrial ecosystems. - Ecology 89: 647-659.

Wigham, B. D. et al. 2003. Reproductive biology of the abyssal holothurian Amperima rosea: an opportunistic response to variable flux of surface derived organic matter? - J. Mar. Biol. Ass. UK 83: 175-188.

Wilmers, C. C. and Post, E. 2006. Predicting the influence of wolf-provided carrion on scavenger community dynamics under climate change scenarios. - Global Change Biol. 12: 403-409.

Wilmers, C. C. et al. 2003a. Resource dispersion and consumer dominance: scavenging at wolf- and hunter-killed carcasses in Greater Yellowstone, USA. - Ecol. Lett. 6: 996-1003.

Wilmers, C. C. et al. 2003b. Trophic facilitation by introduced top predators: grey wolf subsidies to scavengers in Yellowstone National Park. - J. Anim. Ecol. 72: 909-916.

Wilson, E. E. and Wolkovich, E. M. 2011. Scavenging: how carnivores and scavenging structure communities. - Trends Ecol. Evol. 26: 129-135. 